\title{
Improved Calcium Utilization at Motor Nerve Terminals Exposed to Botulinum Neurotoxin in Mice
}

\author{
Ryu FUJIKAWA', Toshiaki ISHII,2, Seiichi KOMORI ${ }^{1,3}$, and Masakazu NISHIMURA ${ }^{1,2}$ \\ 'Department of Pathogenetic Veterinary Science, the United Graduate School of Veterinary Sciences, Gifu University, 1-1 Yanagido, \\ Gifu, 501-1193 Japan; ${ }^{2}$ the Laboratory of Pharmacology, Department of Pathobiological Science, School of Veterinary Science, \\ Faculty of Animal Husbandry, Obihiro University of Agriculture and Veterinary Medicine, Obihiro Hokkaido, 080-8555 Japan; and ${ }^{3}$ the \\ Laboratory of Pharmacology, Faculty of Applied Biological Science, Gifu University, 1-1 Yanagido, Gifu, 501-1193 Japan
}

\begin{abstract}
We examined the fail-safe responses against lowdose botulinum intoxication (botulinum neurotoxin serotype A; $0.05 \mathrm{ng} / 35 \mathrm{~g}$ body weight) in electrically activated in vitro phrenic nerve-diaphragm preparations, since sustained ventilation is critical for the prognosis of clinical botulinum intoxication. At 0 , 1,2 and 4 wks after the peritoneal injection of the toxin, both contractility and neurotransmitter release were measured. There was an increase in directly induced twitch force without affecting directly induced tetanus throughout the observation period. Indirectly induced twitch force decreased by $60 \%$ at 1 wk, which gradually recovered only during the 4-wk observation period. Spontaneous neurotransmitter release, evaluated as the frequency of miniature end plate potentials, was largely abolished 1 wk after the injection and recovered only slightly
\end{abstract}

during the 4-wk period. The effects on spontaneous release were independent of medium $\mathrm{Ca}^{2+}$ concentration. Evoked release, evaluated as quantal content, was also mostly inhibited at $1 \mathrm{wk}$, but it recovered to approximately $50 \%$ of controls at 4 wks. The recovery of quantal content was more prominent at low medium $\mathrm{Ca}^{2+}$ concentration. These results indicated two functional failsafe responses that compensate for the acute inhibitory effect of low dose of botulinum toxin on neuromuscular transmission; increased contractility of muscle, and improved efficiency of evoked quantum release. The increased contractility probably reflects remodeling of muscle fiber composition of the diaphragm. The improved efficiency of evoked quantum release probably involves remodeling of voltage-gated $\mathrm{Ca}^{2+}$ channels, intracellular $\mathrm{Ca}^{2+}$ store sites, or transmitter-releasing apparatuses.

Key words: calcium cooperativity, botulinum neurotoxin, quantal content.

$\mathrm{I}_{\mathrm{n} j}$ Inection of botulinum toxin into muscle prevents neurotransmitter release from motor nerve terminals, and results in long-term paralysis [1-3]. Botulinum neurotoxin serotype A (BoNT/A), one of the most potent toxins known to man, has been used in many experiments to examine its acute and long-term effects. The toxin cleaves out the C-terminus of the 25-kDa synaptosomally associated protein (SNAP-25), which is a cytoplasmic protein that participates in the fusion of synaptic vesicles with the nerve terminal membrane to facilitate neurotransmitter release [4]. Functional recovery is supported by newly synthesized SNAP-25 [5] and subsequent morphological changes, including the formation of new motor nerve branches or sprouts $[2,6]$. These morphological changes appear $1 \mathrm{wk}$ after injection, reach a maximum 4 wks after injection, and disappear after 13 wks after injection [7].

Most studies so far focused on the effects of highdose BoNT/A that causes severe paralysis. However, intoxication with much lower dose is the general clinical situation. A wide safety margin reported for the function of motor nerve terminals $[8,9]$ suggests that several failsafe responses work to compensate for the effect of the low-dose BoNT/A intoxication. The responses induced at low-dose intoxication would be functional rather than morphological.

The purpose of the present study was to examine the fail-safe responses that compensate for the effect of low-dose BoNT/A intoxication. To detect the responses during 4-wk recovery period, we analyzed both muscle contractility and neurotransmission of isolated nervemuscle preparations. We used phrenic nerve-diaphragm preparations because their contraction is continuously driven by the need for ventilation so as to actuate compensatory fail-safe responses. Maintenance of diaphragm function is critical for the clinical prognosis of botulinum intoxication.

Received on Jan 14, 2008; accepted on Sep 25, 2008; released online on Oct 11, 2008; doi:10.2170/physiolsci.RP000908 Correspondence should be addressed to: M. Nishimura, the Laboratory of Pharmacology, Department of Pathobiological Science, School of Veterinary Science, Faculty of Animal Husbandry, Obihiro University of Agriculture and Veterinary Medicine, Obihiro Hokkaido, 080-8555 Japan; and Ryu Fujikawa, Department of Pathogenetic Veterinary Science, the United Graduate School of Veterinary Sciences, Gifu University, Gifu, 501-1193 Japan. E-mail: s13036@st.obihiro.ac.jp 


\section{R. FUJIKAWA et al.}

\section{MATERIALS AND METHODS}

Animals. Male and female mice (7 wks-old) were intraperitoneally injected with BoNT/A $(0.05 \mathrm{ng} / 35 \mathrm{~g}$ body weight) and killed at $0,1,2$, or 4 wks after injection ( $n$ $=6 /$ group). Left phrenic nerve-diaphragm preparations were dissected from the mice. Those killed at $0 \mathrm{wks}$ were not injected with the toxin and served as controls. All procedures were approved by our institutional review committee and followed the guidelines of the Physiological Society of Japan for the care and use of experimental animals.

Botulinum toxin. BoNT/A was purchased from Wako Pure Chemical Industries (Osaka, Japan). After dilution with $0.05 \mathrm{~mol} / l$ acetate and $0.2 \mathrm{~mol} / l \mathrm{NaCl}(\mathrm{pH} 6.0)$ buffer, the mice were injected with an amount of toxin that slightly inhibited locomotor activity.

Media and hemidiaphragm preparation. All experiments were performed on isolated left hemidiaphragm preparations [10]. The preparation was soaked in a KrebsRinger solution with the following composition (mM): $\mathrm{NaCl}, 136 ; \mathrm{KCl}, 5 ; \mathrm{CaCl}_{2}, 2 ; \mathrm{MgCl}_{2}, 1 ; \mathrm{NaHCO}_{3}, 15$; glucose, 11 . Other bathing solutions containing $0.55,0.60$, 0.66 , or $0.72 \mathrm{mM} \mathrm{Ca}^{2+}$ and $5 \mathrm{mM} \mathrm{Mg}^{2+}$ (low $\mathrm{Ca}^{2+}$-high $\mathrm{Mg}^{2+}$ bathing solutions) were also prepared for measuring end plate potentials (EPPs). These solutions were bubbled with a mixture of $95 \% \mathrm{O}_{2}$ and $5 \% \mathrm{CO}_{2}$ and kept at $\mathrm{pH} 7.3$ and $37^{\circ} \mathrm{C}$. The preparation was equilibrated in the appropriate bathing solution for at least $30 \mathrm{~min}$ before any treatments. The temperature of the solution was held constant using an external water jacket and a thermoregulatory device (Thermominder SM-05R, Taitec, Koshigaya, Japan).

Tension Recording. One end of the site of insertion into the rib cage of the left hemidiaphragm with its phrenic nerve was fixed, and the central tendon was attached to a force-displacement transducer (TB-652T, Nihon Kohden, Tokyo, Japan). The phrenic nerve or muscle layer was stimulated through a suction electrode connected to an electronic square-pulse generator (SEN-3201, Nihon Kohden) in the standard bathing solution. The nerve trunk was stimulated with supermaximal voltage at 0.1ms duration (indirectly induced twitch [IT]) and the muscle also at 1-ms duration (directly induced twitch [DT]). Resulting isometric twitches were recorded on a thermal array recorder (AD-100F, Nihon Kohden).

TOF test. Trains of four stimulations (TOF stimulation, $2 \mathrm{~Hz}$ for $2 \mathrm{~s}$ every $15 \mathrm{~s}$ ) were applied to the nerve and muscle layer. These stimuli evoked four consecutive twitches (T1, T2, T3, T4). The TOF ratio of the fourth twitch to the first twitch (T4/T1) was calculated. The TOF ratio was approximately 1 when the muscle was stimulated and greater than 1 when the motor nerve was stimulated. A reduction in neurotransmitter release should produce a ratio that is smaller than 1 [11].

Electrophysiological measurements. Intracellular recordings were made using glass microcapillary electrodes filled with $3 \mathrm{M} \mathrm{KCl}$ with a resistance of 4-6 $\mathrm{M} \Omega$. The electrode was inserted into muscle fibers near the end plate regions. The signals were fed through a highimpedance unity-gain preamplifier (MEZ-8201, Nihon Kohden) and displayed on an oscilloscope (VC-11, Nihon Kohden). The amplitudes of miniature end plate potentials (mEPPs) that were at least $0.05 \mathrm{mV}$ were counted by a histogram analyzer (QC-111J, Nihon Kohden). The mEPPs were recorded for successive periods of approximately $1 \mathrm{~min}$ after exposure to a given solution, and the mean mEPP frequency was calculated. EPPs were evoked by stimulation of the phrenic nerve with 128 square pulses of 0.1-ms duration and supermaximal voltage at 1.5$\mathrm{s}$ intervals using a suction electrode in the low-calcium bathing solutions. The quantal content (m) was estimated by the method of failures from

$\mathrm{m}=\log _{\mathrm{e}}(\mathrm{N} / \mathrm{No})$

in which $\mathrm{N}$ is the number of trials and No is the number of failures [12].

Calcium cooperativity was defined as the slope of the line of log quantal content plotted against the log calcium concentration.

Statistical methods. Data were analyzed by a Student's $t$-test after an F test. In Figs. 4 and 5, data also were analyzed by a one-way analysis of variance (ANOVA) test. In Fig. 7, data were analyzed by a comparison of two regression slopes, and a probability value of less than 0.05 was considered statistically significant.

\section{RESULTS}

The dose of BoNT/A selected for intraperitoneal injections was not lethal to mice. This dose produced intoxication for a few days after injection. The mice recovered and regained movement and feeding abilities, thus becoming able to perform usual daily activities. Figure 1 shows the effects of BoNT/A in vivo intoxication on neuromuscular transmission in the isolated phrenic nervediaphragm preparations. The ratio of IT/DT was calculation as a quantitative estimate of the toxin effects on the neuromuscular transmission. BoNT/A initially reduced the ratio to approximately $40 \%$ of controls at $1 \mathrm{wk}$ after the injection. The ratio recovered to $55 \%$ at $2 \mathrm{wks}$, and $70 \%$ at 4 wks. Thus, the toxin transiently inhibited neuromuscular transmission, which recovered significantly over the 4-wk study period.

The effects of the toxin on DT were examined (Fig. 2). The DT amplitude increased at 1 and 2 wks after the toxin injection. This effect weakened, but continued at 4 wks. On the contrary, chronic exposure to the toxin did not affect directly evoked tetanus (data not shown). The TOF test showed a selective inhibitory effect on IT, implying that neuromuscular transmission was impaired (Fig. 3). This impairment partially recovered within the 


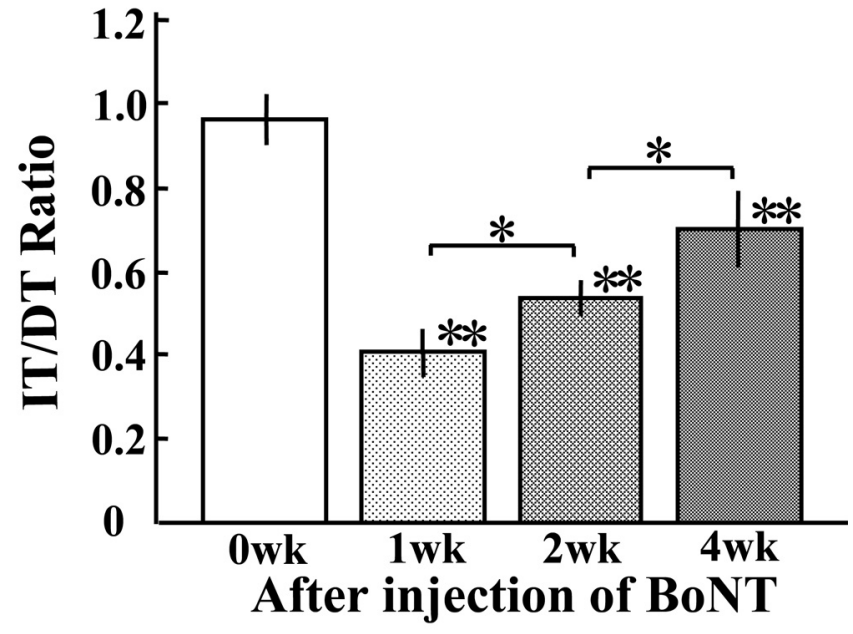

Fig. 1. Effect of BoNT/A in vivo intoxication on the IT/DT ratio in isolated left hemidiaphragm preparations from control mice and mice 1, 2, and 4 wks after BoNT/A injection. All preparations were trimmed to be $4 \mathrm{~mm}$ wide. The ratio was calculated from the amplitude of IT divided by the amplitude of DT. Supermaximal voltages elicited both IT and DT. Results are means \pm SE of six preparations. ${ }^{*} P<0.05$ and ${ }^{* *} P$ $<0.01$ vs. control.

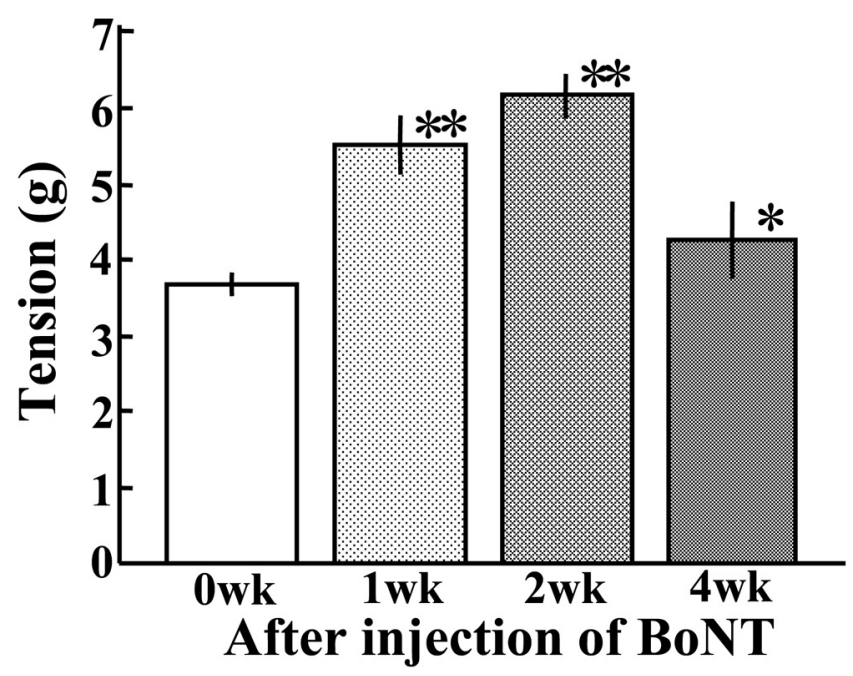

Fig. 2. Effect of BoNT/A in vivo on DT amplitude in isolated left hemidiaphragm preparations from control mice and mice 1, 2, and 4 wks after BoNT/A injection. All preparations were trimmed to be $4 \mathrm{~mm}$ wide. Results are means \pm SE of six preparations. ${ }^{*} P<0.05$ and ${ }^{* *} P<0.01$ vs. control.

4-wk observation period. In contrast, the TOF ratio of the DT increased at 1 and 2 wks after the toxin treatment.

To confirm that the toxin inhibited neurotransmitter release, we examined the effect on spontaneous and evoked output of neurotransmitter in the diaphragm. Spontaneous release was estimated by measuring mEPP frequency. The toxin injection reduced mEPP frequency to almost zero (Fig. 4), which recovered only slightly

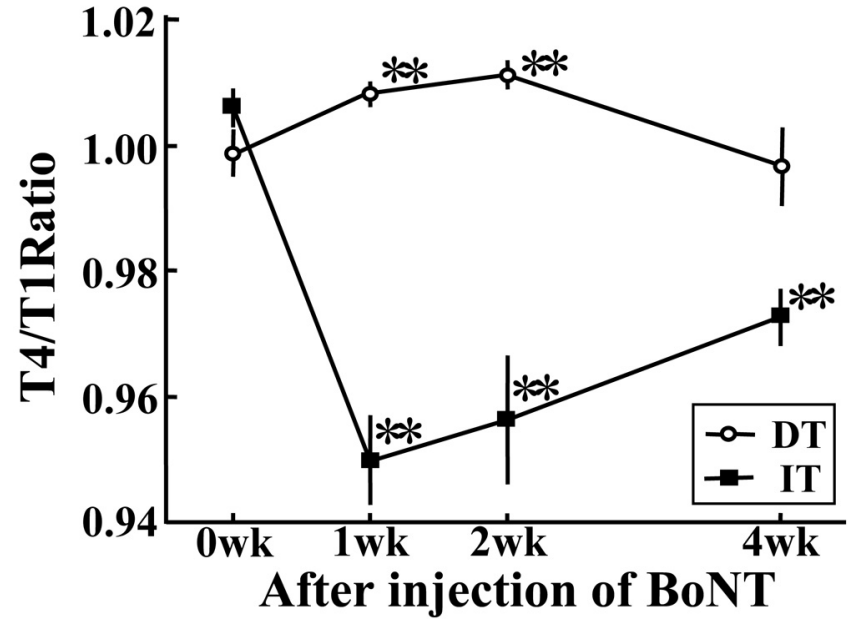

Fig. 3. Effect of BoNT/A in vivo on TOF ratios of IT and DT in isolated left hemidiaphragm preparations from control mice and mice 1, 2, and 4 wks after BoNT/A injection. The TOF ratio was defined as the amplitude of the fourth twitch to the amplitude of the first twitch, calculated from four sequential twitches. Results are means \pm SE of six preparations. ${ }^{* *} P<$ 0.01 vs. control.

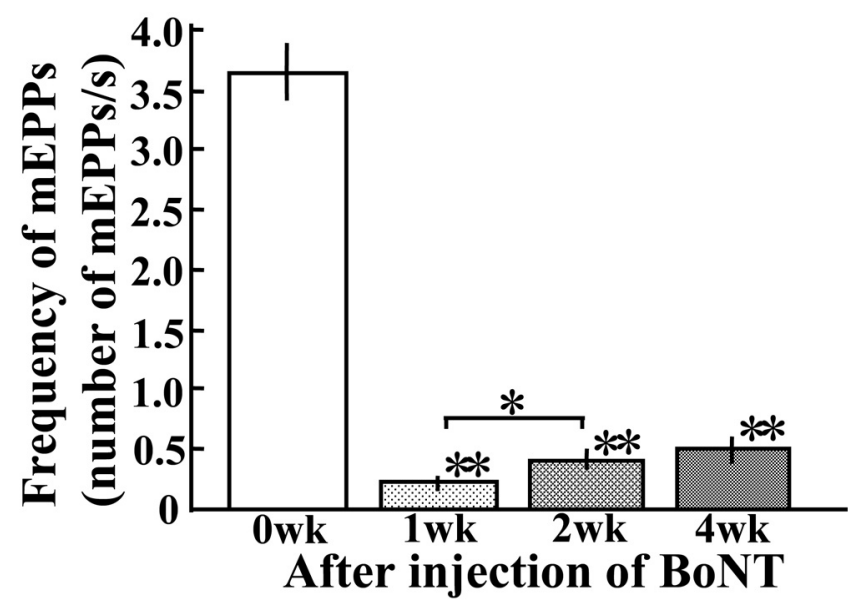

Fig. 4. Effect of BoNT/A in vivo on mEPP frequency in isolated left hemidiaphragm preparations from control mice and mice 1, 2, and 4 wks after BoNT/A injection. mEPPs were measured in a Krebs-Ringer solution with $0.60 \mathrm{mM} \mathrm{Ca}^{2+}$ and $5 \mathrm{mM} \mathrm{Mg}^{2+}$. Frequency per second is shown. The results are means \pm SE of six preparations. ${ }^{*} P<0.05$ vs. 1 wk and ${ }^{* *} P<$ 0.01 vs. control.

during the observation period. The amplitude of mEPP showed no marked change during the period (data not shown). Evoked release was evaluated by its quantal content (Fig. 5). The toxin drastically reduced the content 1 wk after the injection. The content was gradually restored and reached $50 \%$ of controls at 4 wks. Thus, the inhibitory effect more potently affected the mEPP frequency, and the recovery of the quantal content was remarkable. 


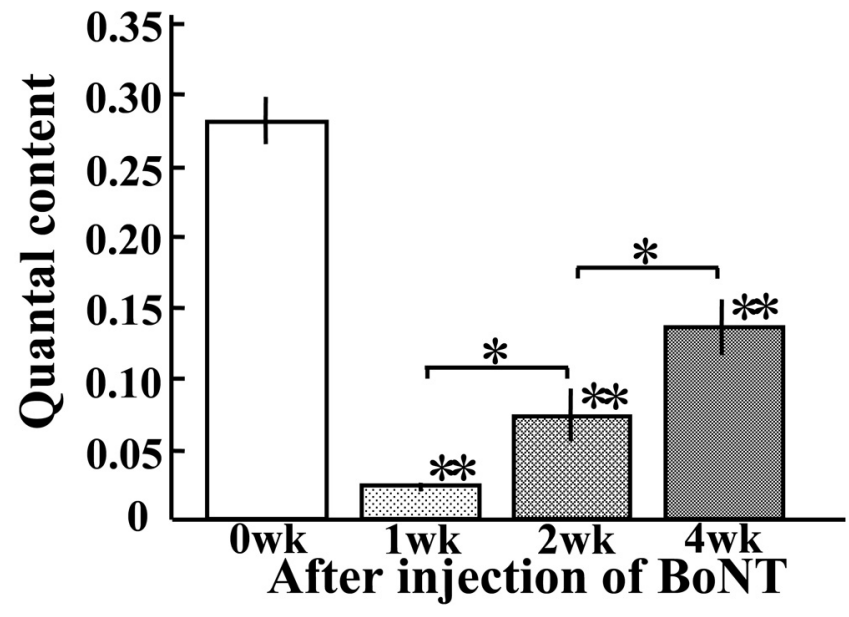

Fig. 5. Effect of BoNT/A in vivo on the quantal content of EPPs in isolated left hemidiaphragm preparations from control mice and mice 1, 2, and 4 wks after BoNT/A injection. EPPs were measured in Krebs-Ringer solution with $0.60 \mathrm{mM}$ $\mathrm{Ca}^{2+}$ and $5 \mathrm{mM} \mathrm{Mg}^{2+}$. Quantal content was calculated by the method of failures. Results are means \pm SE of six preparations. ${ }^{*} P<0.05$ vs. 2 wks and ${ }^{* *} P<0.01$ vs. control.

Based on the differential effects of BoNT/A on mEPP and evoked EPP, we further examined the dependency of EPPs on $\mathrm{Ca}^{2+}$ concentration in the medium. As shown in Fig. 6, mEPP frequency remained almost constant regardless of the $\mathrm{Ca}^{2+}$ concentration. On the other hand, the quantal content of evoked EPP depended significantly on $\mathrm{Ca}^{2+}$ concentration. In Fig. 7, we plotted the logarithmic values of the quantal content against the logarithmic values of $\mathrm{Ca}^{2+}$ concentration. The plot gave regression lines with different slopes. The slope of $1 \mathrm{wk}$ after the toxin injection (3.7) was similar to that of controls (3.7), but was significantly reduced after 2 wks (1.9) and 4 wks (1.5). This reflects that quantal content recovered more prominently at the lower $\mathrm{Ca}^{2+}$ conditions, suggesting that medium $\mathrm{Ca}^{2+}$ is more effectively utilized during the recovery phase from BoNT/A intoxication.

\section{DISCUSSION}

\section{Acute effect of BoNT/A}

The present observations concerning the IT/DT ratio (Fig. 1), the mEPP frequency (Fig. 4), and the quantal content of evoked EPP (Fig. 5) all confirmed that the acute effect of botulinum intoxication markedly inhibited neuromuscular synaptic transmission. The $\mathrm{T} 4 / \mathrm{T} 1$ ratio of IT (Fig. 3) was proposed to be a convenient parameter that reflects neuromuscular transmission blockade because the train of $2 \mathrm{~Hz}$ stimulation on an impaired motor terminal induced efficient neurotransmitter depletion [12]. In the present study, the T4/T1 ratio of IT was always greater than 1 in controls, but less than 1 following the exposure to BoNT/A, confirming that the ratio could

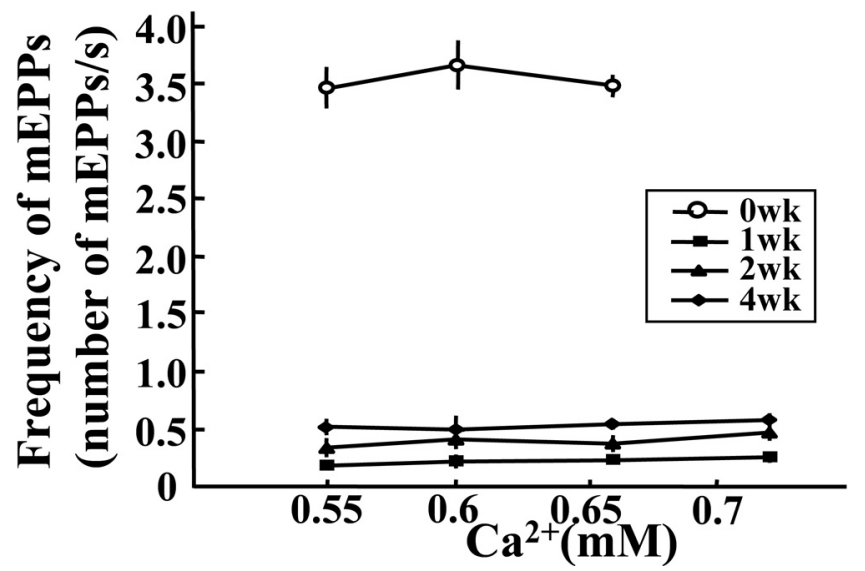

Fig. 6. Dependency of mEPPs frequency on calcium concentrations in the medium in isolated left hemidiaphragm preparations derived from control mice and mice at 1, 2, and 4 wks after BoNT/A injection. mEPPs were measured in Krebs-Ringer solutions with four $\mathrm{Ca}^{2+}$ concentrations $(0.55$, $0.60,0.66$, and $0.72 \mathrm{mM}$ ) and $5 \mathrm{mM} \mathrm{Mg}^{2+}$. The results are means \pm SE of six preparations.

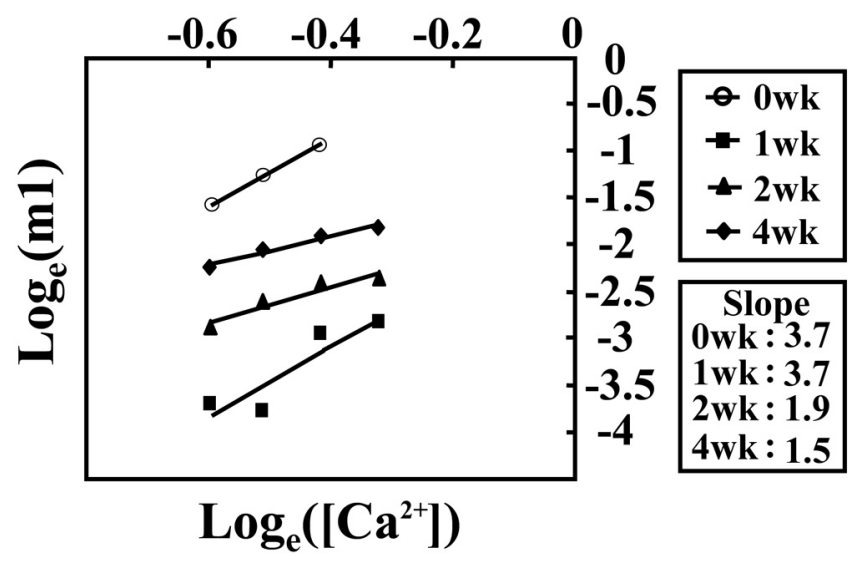

Fig. 7. Logarithmic relationship between quantal contents and calcium concentrations in isolated left hemidiaphragm preparations from control mice and mice at 1,2, and 4 wks after BoNT/A injection. Quantal contents were calculated with four $\mathrm{Ca}^{2+}$ concentrations $(0.55,0.60,0.66$, and 0.72 $\mathrm{mM}$ ) and $5 \mathrm{mM} \mathrm{Mg}^{2+}$. Each point represents the mean of six measurements. The slope for each data set was calculated and is shown in the inset.

conveniently detect impaired synaptic transmission without referring to directly stimulated force.

\section{Reinforcement of DT during recovery period}

During the 4-wk recovery period from the acute effect of intoxication, two functional fail-safe responses were detected: an increase in the DT force of a $4 \mathrm{~mm}$-wide diaphragm (Fig. 2) and the marked recovery of evoked quantum release at the motor nerve terminals (Fig. 5).

The increase of DT amplitude was not accompanied 
by the increase of directly induced tetanic force (data not shown). A similar selective increase in DT beyond the control was reported in the denervated diaphragm by Shindoh and co-workers [13]. Observing the prolonged time course of twitch contraction and histological staining patterns of the denervated diaphragm, they ascribed the recovery to be a consequence of the selective atrophy of fast-twitch muscle fibers. Zhan \& Sieck also reported a selective atrophy of fast-twitch fibers after denervation and chronic tetrodotoxin intoxication in the diaphragm and also in the medial gastrocuemius muscle [14]. Consistently with the selective atrophy of fast-twitch fibers after prolonged deactivation of the muscle, BoNT/A injection was reported to induce a sustained decrease of directly induced both twitch and tetanus force in the extensor digitorum longus and tibialis anterior muscles, which are rich in fast-twitch fibers [15]. We consider that the selective DT increase observed in the present study also reflects increased contribution from slow-twitch fibers resulting from the selective atrophy of fast-twitch fibers. This is because the T4/T1 ratio of DT was also increased during the recovery period (Fig. 3). Successive DT contractions of slow-twitch fibers at $2 \mathrm{~Hz}$ would partially merge to increase the T4/T1 ratio. Thus it is reasonable that the T4/T1 ratio and the IT/DT ratio concomitantly returned to the original values at 4 wks after the BoNT/A injection.

Along with the selective atrophy of fast-twitch fibers, Zhan \& Sieck observed selective hypertrophy of slowtwitch fibers [14]. Although we did not measure the thickness of our $4 \mathrm{~mm}$-wide diaphragm specimens, the compensative hypertrophy of slow-twitch fibers may have prevented the diaphragm from overall atrophy to maintain ventilation. We consider that a part of the increased DT amplitude would reflect hypertrophy of slow-twitch muscle fibers also.

\section{Efficient utilization of external $\mathrm{Ca}^{2+}$ at the motor nerve terminals}

The most surprising result obtained in the present study is that the evoked transmitter release (evaluated as quantal content of evoked EPP; Fig. 5) recovered more prominently than the spontaneous transmitter release at rest (evaluated as mEPP frequency; Fig. 4). It is generally considered that the mEPP frequency is determined by the number of mature synaptic vesicles and the concentration of internal $\mathrm{Ca}^{2+}$ in the resting motor terminals [11]. The steady concentration level of internal $\mathrm{Ca}^{2+}$ at rest represents the balance point between $\mathrm{Ca}^{2+}$ inflow and export at the motor nerve terminals. Since mEPP frequency did not depend on external $\mathrm{Ca}^{2+}$ throughout the present 4-wk recovery period (Fig. 6), we consider that the resting motor terminals are able to regulate their $\mathrm{Ca}^{2+}$ export system to compensate for the reduced $\mathrm{Ca}^{2+}$ inflow so as to keep internal $\mathrm{Ca}^{2+}$ concentration at the physiological level throughout the recovery period. It then follows that the reduced $\mathrm{mEPP}$ frequency would represent the reduced number of mature synaptic vesicles that are readily released. The prominent recovery of quantal content observed during the 4 -wk recovery period would therefore represent the improved efficiency of the mechanisms that release the transmitter when evoked.

The recovery extent of the quantal content was found more prominent at low external $\mathrm{Ca}^{2+}$ concentrations (Fig. 7). Similar external $\mathrm{Ca}^{2+}$ dependency of quantal content has been observed in motor nerve terminals blocked chronically with tetrodotoxin cuff [16]. The evoked quantum release preferentially efficient at low external $\mathrm{Ca}^{2+}$ concentration may be one of the general features of failsafe responses induced by the chronic deactivation of neuromuscular units.

It is well documented that the surge of internal $\mathrm{Ca}^{2+}$ concentration evokes quantal transmitter release. The surge is due to a transient increase in the inflow of external $\mathrm{Ca}^{2+}$ and $\mathrm{Ca}^{2+}$ release from the $\mathrm{Ca}^{2+}$ store sites in the motor nerve terminals. Therefore the efficiently evoked quantum release would reflect enhanced $\mathrm{Ca}^{2+}$ inflow, enhanced $\mathrm{Ca}^{2+}$ release from the store sites, or sensitized quantum release in response to internal $\mathrm{Ca}^{2+}$ elevation, as follows.

The possibility of enhanced $\mathrm{Ca}^{2+}$ inflow that preferentially works at low external $\mathrm{Ca}^{2+}$ is supported by the evidence that several types of voltage-gated $\mathrm{Ca}^{2+}$ channels have been reported to develop during the recovery period from BoNT intoxication [17-19]. In normal condition, the $\mathrm{P} / \mathrm{Q}$-type channel is generally considered to induce evoked quantum release [20]. Some of the $\mathrm{Ca}^{2+}$ channels specific to the recovery period may be partially inactivated at physiological external $\mathrm{Ca}^{2+}$ concentration. If such channels at the active state provide additional $\mathrm{Ca}^{2+}$ permeability, internal $\mathrm{Ca}^{2+}$ concentration would rapidly rise closer to the steady level within a limited period of activation, allowing effective utilization of low external $\mathrm{Ca}^{2+}$.

Since BoNT/A-intoxicated motor nerve terminals would be actively remodeling to recover, new $\mathrm{Ca}^{2+}$ store sites may also develop during the recovery period. If these newly developed $\mathrm{Ca}^{2+}$ store sites are evoked to release $\mathrm{Ca}^{2+}$, their effect would be more prominently observed when $\mathrm{Ca}^{2+}$ inflow is limited. Therefore evoked transmitter release would recover preferentially at low external $\mathrm{Ca}^{2+}$.

Newly developed quantum-releasing apparatuses may work sensitively in response to internal $\mathrm{Ca}^{2+}$ elevation. Since the population of newly developed apparatuses is naturally limited, their releasing capacity readily saturated when internal $\mathrm{Ca}^{2+}$ is considerably increased. The remaining mature quantum-releasing apparatuses having low sensitivity to internal $\mathrm{Ca}^{2+}$ would supplement additional quantum release at physiological external $\mathrm{Ca}^{2+}$.

Nevertheless, quantal content at low external $\mathrm{Ca}^{2+}$ is a 
better index of the progress of functional recovery after BoNT/A intoxication. This index would reflect newly developed voltage-dependent $\mathrm{Ca}^{2+}$ channels, $\mathrm{Ca}^{2+}$ store sites, or quantum-releasing apparatuses that may reside mainly in newly formed motor nerve branches or sprouts. If this happens, quantum release at physiological external $\mathrm{Ca}^{2+}$ would mainly reflect the remaining and recovered capacity in the parent terminals.

\section{Postsynaptic remodeling}

Postsynaptic acetylcholine receptor is another candidate site where functional fail-safe responses work. It has been reported that the number and distribution area of acetylcholine receptors were increased in rat diaphragm [21] and hindlimb [22] after treatment with high-dose BoNT. In the present case of low-dose intoxication, however, we consider that increases in the number and distribution area of effective acetylcholine receptors do not contribute significantly, at least not at the parent motor nerve terminals. This is because the recovery ratio of IT paralleled with the recovery of quantal content (suppression at $1 \mathrm{wk}$ halved at $4 \mathrm{wks}$; Figs. 1 and 5) at physiological external $\mathrm{Ca}^{2+}$, and the amplitudes of mEPP remained almost constant during the recovery period (data not shown).

In conclusion, we found two long-term functional failsafe responses to low-dose BoNT/A intoxication in isolated phrenic nerve-diaphragm specimens: increased DT amplitude of muscle specimens and effectively evoked quantum release at motor nerve terminals. The increased DT amplitude would reflect an increased contribution of slow-twitch fibers. The preferential recovery of evoked quantum release at low external $\mathrm{Ca}^{2+}$ would represent newly developing quantum-releasing capacity of the motor nerve terminals. We consider that these functional fail-safe responses are not specific to the diaphragm, but may be specific to low-dose BoNT/A intoxication.

\section{REFERENCES}

1. Duchen LW. Changes in motor innervation and cholinesterase localization induced by botulinum toxin in skeletal muscle of the mouse: differences between fast and slow muscles. J Neurol Neurosurg Psychiatry. 1970;33:40-54.

2. Angaut-Petit D, Molgó J, Comella JX, Faille L, Tabti N. Terminal sprouting in mouse neuromuscular junctions poisoned with botulinum type A toxin: morphological and electrophysiological features. Neuroscience. 1990;37:799-808.
3. Molgo J, Comella JX, Angaut-Petit D, Pecot-Dechavassine M, Tabti N, Faille L, Mallart A, Thesleff S. Presynaptic actions of botulinal neurotoxins at vertebrate neuromuscular junctions. J Physiol (Paris). 1990;84:152-66.

4. Blasi J, Chapman ER, Link E, Binz T, Yamasaki S, De Camilli P, Südhof TC, Niemann H, Jahn R. Botulinum neurotoxin A selectively cleaves the synaptic protein SNAP-25. Nature. 1993;365:160-3.

5. Osen-Sand A, Catsicas M, Staple JK, Jones KA, Ayala G, Knowles J, Grenningloh G, Catsicas S. Inhibition of axonal growth by SNAP-25 antisense oligonucleotides in vitro and in vivo. Nature. 1993;364:445-8.

6. Duchen LW, Strich SJ. The effects of botulinum toxin on the pattern of innervation of skeletal muscle in the mouse. Q J Exp Physiol Cogn Med Sci. 1968:53:84-9.

7. de Paiva A, Meunier FA, Molgó J, Aoki KR, Dolly JO. Functional repair of motor endplates after botulinum neurotoxin type A poisoning: biphasic switch of synaptic activity between nerve sprouts and their parent terminals. Proc Natl Acad Sci U S A. 1999:96:3200-5.

8. Paton WD, Waud DR. The margin of safety of neuromuscular transmission. J Physiol. 1967;191:59-90.

9. Nishimura M, Taquahashi Y, Satoh E, Shimizu Y, Tsusaki H. Chronic exposure to neomycin specifically sensitizes motor nerve terminals to calcium ions. Biomed Res. 1995;16:399-403.

10. Bülbring $E$. Observations on the isolated phrenic nerve diaphragm preparation of the rat. Br J Pharmacol. 1946;1:38-61.

11. Hughes R. Assessment of neuromuscular blockade using tetanic, single-twitch and train-of-four responses: discussion paper. J R Soc Med. 1984;77:399-405.

12. Crawford AC. The dependence of evoked transmitter release on external calcium ions at very low mean quantal contents. J Physiol. 1974;240:255-78.

13. Shindoh C, Hida W, Kurosawa H, Ebihara S, Kikuchi Y, Takishima T, Shirato K. Effects of unilateral phrenic nerve denervation on diaphragm contractility in rat. Tohoku J Exp Med. 1994;173:291-302.

14. Zhan WZ, Sieck GC. Adaptations of diaphragm and medial gastrocnemius muscles to inactivity. J Appl Physiol. 1992;72:1445-53.

15. Morbiato L, Carli L, Johnson EA, Montecucco C, Molgó J, Rossetto O. Neuromuscular paralysis and recovery in mice injected with botulinum neurotoxins A and C. Eur J Neurosci. 2007;25:2697-704.

16. Wang X, Engisch KL, Li Y, Pinter MJ, Cope TC, Rich MM. Decreased synaptic activity shifts the calcium dependence of release at the mammalian neuromuscular junction in vivo. J Neurosci. 2004;24:10687-92.

17. Uchitel OD, Protti DA, Sanchez V, Cherksey BD, Sugimori M, Llinás R. P-type voltage-dependent calcium channel mediates presynaptic calcium influx and transmitter release in mammalian synapses. Proc Natl Acad Sci U S A. 1992;89:3330-3.

18. Bowersox SS, Miljanich GP, Sugiura Y, Li C, Nadasdi L, Hoffman BB, Ramachandran J, Ko CP. Differential blockade of voltage-sensitive calcium channels at the mouse neuromuscular junction by novel omega-conopeptides and omega-agatoxin-IVA. J Pharmacol Exp Ther. 1995;273:248-56.

19. Hong SJ, Chang CC. Inhibition of acetylcholine release from mouse motor nerve by a P-type calcium channel blocker, omega-agatoxin IVA. J Physiol. 1995;482:283-90.

20. Santafé MM, Urbano FJ, Lanuza MA, Uchitel OD. Multiple types of calcium channels mediate transmitter release during functional recovery of botulinum toxin type A-poisoned mouse motor nerve terminals. Neuroscience. 2000;95:227-34.

21. Simpson LL. The effects of acute and chronic botulinum toxin treatment on receptor number, receptor distribution and tissue sensitivity in rat diaphragm. J Pharmacol Exp Ther. 1977;200:343-51.

22. Bambrick L, Gordon T. Acetylcholine receptors and sodium channels in denervated and botulinum-toxin-treated adult rat muscle. J Physiol. 1987;382:69-86. 